\title{
An Investigation of the Operational Efficiency of School Management through Innovative Teaching via Digital Mobile E-learning: DEA and Data mining Methodology
}

\author{
Fu-Hsiang Kuo ${ }^{1}$
}

\begin{abstract}
The goal of this research is to find out the factors or Determinants Affecting School Efficiency have the school to implement digital mobile e-learning and future tendency. The empirical results of this research indicate the following results: (1) In this study, we find that Importing digital mobile e-learning can really enhance the efficiency of school management. Furthermore, all these schools are located in Taipei City or New Taipei City. (2) Lastly, we also apply the data mining methodology to find that the teacher-student ratio, tablet PC numbers, technical teacher ratio, the total equipment expenses associated with tablet PC, School location and School attribute are important determinants for affecting the efficiency of school management. On the other hand, When the number of students decreases, too many teachers and technical teachers, as well as redundant equipment, etc., will become a burden on the school. Finally, these factors will affect school efficiency. The results of this research can also be the reference for educational authorities when formulating policies and regulations for promoting digital mobile e-learning.
\end{abstract}

JEL classification numbers: C55, I28

Keywords: Technical efficiency, Digital mobile e-learning, Data envelopment analysis (DEA), Big data application, Data mining methodology.

${ }^{1}$ Department of Finance, National Yunlin University of Science and Technology, Yunlin City Taiwan, R. O. C.

Article Info: Received: November 17, 2020. Revised: December 5, 2020.

Published online: December 17, 2020. 


\section{Introduction}

The education is a key element in the development of the nations and plays an important role in human capital development (Garrett, 2010). Taiwan nearly half a century ago, the national compulsory education from 6 years have extended to 9 years. Thus, the national compulsory education of 9 years education policy that it has helped Taiwan to Promote economic growth and development. Up till this day, the Government still extended our compulsory education to 12 years. So that is hope, it could cultivate sufficient human resources to create a Taiwan economic miracle once again. Education today revolves more around encouraging the student to awaken their curiosity and desire to learn.

On the other hand, Taiwan to facing the challenge of the low birth rate which also significantly impacts on educational institutes. Hence, schools need to change or adjust the teaching techniques and study skills to increase schools' competitiveness. We all know that the new learning model of the digital mobile e-learning, or "MLearning" model, offers modern ways to support learning process through mobile devices, such as handheld and tablet computers, MP3 players, smartphones and mobile phones. Thus, the teachers of today have to learn new teaching techniques to master the activity approach, up-to-date teaching aids, and many other innovations.

The Ministry of Education in Taiwan have begun to import the digital mobile elearning in 2012. By 2014 donated to approximately 101 schools nationwide, which allowed students and teachers in various counties and cities to develop the digital mobile e-learning by utilizing wireless networks to enhance teaching quality and increase students' interest level. Until 2017, over 100 schools have used the elearning model throughout Taiwan. The digital mobile e-learning has thus become a topic of interest to both the academics and the private sector. Public and private schools alike are striving to highlight their respective strengths and to increase their competitive advantages, and meet students' and parents' needs, and establish unique attributes through innovative operations, so schools can win parents' and students' favorable consideration (Chiang, 2009).

During the past studies that the objective of promoting the digital mobile e-learning in education is to improve students' interest in learning. Moreover, this new learning model indeed increases students' interest in learning. Hence, the digital mobile elearning to teach is an important and emerging trend in the classroom.

Furthermore, the DEA model is one of the most popular approaches in management science for evaluating the relative efficiency of DMus. The main reason is the DEA model a few of the characteristics that make it powerful are (Cook et al., 2014):

- DEA can handle multiple inputs and multiple output models.

- It doesn't require an assumption of a functional form relating inputs to outputs.

- DMUs are directly compared against a peer or combination of peers.

But the DEA model will be some missing.

- Since DEA is an extreme point technique, noise (even symmetrical noise with zero means) such as measurement error can cause significant problems. 
- DEA is good at estimating "relative" efficiency of a DMU but it converges very slowly to "absolute" efficiency. In other words, it can tell you how well you are doing compared to your peers but not compared to a "theoretical maximum."

- Since DEA is a nonparametric technique, statistical hypothesis tests are difficult and are the focus of ongoing research.

The DEA model has been recognized as a valuable analytical research instrument and a practical decision support tool and it has been credited for not requiring a complete specification for the functional form of the production frontier nor the distribution of inefficient deviations from the frontier. Rather, The DEA model requires general production and distribution assumptions only. However, if the DEA model assumptions are too weak, inefficiency levels may be systematically underestimated in small samples. In addition, erroneous assumptions may cause inconsistency with a bias over the frontier. Consequently, DMUs are treated as black boxes (Färe and Grosskopf, 2000).

On the other hand, Priyadharsini and Thanamani (2014) pointed out that Data mining is often described as the process of discovering correlations, patterns, trends, or relationships by searching through a large amount of data stored in repositories, corporate databases, and data warehouses. Thus, to used data mining tools and techniques are being developed to solve this problem through automation and looking for the data relationships. Further, data mining must also be considered as an iterative process that requires goals and objectives to be specified Data mining is used to find or generate new useful information's from a large amount of data base. Finally, it is a process of extracting previously unknown and processable information from large databases and using it to make important business decisions. So, in order to solve its black boxes problem. Recently, some researchers have attempted to integrate Big data into DEA to evaluate the efficiency of decisionmaking units (DMUs) (Chen and Jia, 2017). Also, we find used the Big data resources and increase their performance (McAfee and Brynjolfsson, 2012). Accordingly, the science of Big data has been applied to help researchers, planners, and policymakers. Big data is a term from the dataset which is huge and complex (Ohlhorst, 2012). Besides, Part of the research shows the Data mining is often described as the process of discovering correlations, patterns, trends or relationships by searching through a large amount of data stored in repositories, corporate databases, and data warehouses. Humans, in that sense, are limited by information overload; thus, new tools and techniques are being developed to solve this problem through automation (Rohanizadeh and Bameni, 2009). Such as the CRISP-DM model to help users obtain the best data to provide the most responsive information to address their needs. The evolution and development of finding the right data for decision-making (Chapman et al., 2000).

In recent years, schools in various counties and cities in Taiwan have gradually introduced education reforms and innovative teaching such as the digital mobile elearning. A good deal of literature has reported that the digital mobile e-learning can increase students' interest in learning as well as their motivation to learn. However, whether the high schools that have introduced mobile digital learning to 
enhance classroom teaching, increase in-classroom learning effectiveness, attracting student attendance, and in turn raising schools' operational efficiency remains a topic not yet widely addressed in the literature published domestically. Relevant theoretical foundations are likewise not widely and very litter attention has been given specifically to new learning perspectives to affect the efficiency of school management. Hence, what prompted the undertaking of the current study was to better understand the actual teaching in the field by analyzing appropriate cases where schools derive suitable policy recommendations for schools' operational efficiency. Specifically, we will apply the DEA model to compute and analyze the operational efficiencies of schools through Innovative Teaching via digital mobile e-learning in this study. In view of Data mining model, it is the process of discovering correlations, patterns, trends etc. by searching through a large amount of data stored in repositories. And, finally, we will use data mining methodology to explore, analyze that for discovering correlations, patterns, trends, etc. which to find could be thought as determinants or factors affecting the relative operational efficiencies of schools.

This structure of this paper is as follows: Section 1 introduces the research background and goal of this research. Section 2 reviews the conceptual framework and the overview of policy. Section 3 introduces our methodology. Section 4 presents empirical results, and Section 5 provides the concluding remarks.

\section{Review of Literature}

We all know that mobile technology is defined as any small device with an internet connection and edit functionality that can connect to the internet, and the digital mobile e-learning to teach is an important and emerging trend in the classroom. Furthermore, the digital mobile e-learning emphasizes ubiquitous learning (ulearning), which is the notion that learning can occur at any time or place, not merely in schools or classrooms (Hwang et al., 2008). Thus, many researchers have examined the impact of technologies and the development of communication technologies on teaching effectiveness (Eristi et al., 2011; Martin et al., 2011; Suki and Suki, 2011). As a result, in recent years it has increased noticeably that the various types of advanced technologies which have been introduced into education including wearable technology (Vallurupalli et al., 2013), smart boards (Al-Qirim, 2011; Gursul and Tozmaz, 2010), mobile devices (Williams and Pence 2011; ElGayar et al., 2011; Eristi et al., 2011), and smart classrooms (Simsek et al., 2010). Over the past few years, several studies have been made on the digital mobile elearning. Like for the school districts and universities across the country are purchasing tablets and other mobile devices in massive quantities for innovative use in classrooms (Lawrence, 2012; Price, Jewitt and Crescenzi, 2015; Tate, 2012). The successful use of the digital mobile e-learning in teaching cases abound (i.e., success stories). For example, many studies have indicated the importance of using tablets during classroom instruction as a way to facilitate student learning (Ifenthaler and Schweinbenz, 2013a, b, 2016; Banister, 2010). Furthermore, the Gikas and Grant 
(2013) found that the uses of mobile devices with multiple applications allow students to access information, interact with peers and teachers, and collaborate in order to construct knowledge. Thus, these technologies make it possible to join different fields of knowledge and new techniques (such as Augmented Reality (AR)) assimilate into the digital mobile e-learning. Thus, it is possible to find interesting new features for users and software developers, enabling the creation of content related to AR activities. This scenario has seen a practical incorporation into various fields of knowledge, among which are education and heritage, where there has been the important implementation of thematic content, creating a new way to display and disseminate information present in the territory.

On the other hand, in recent years, Big data related technologies developed greatly and rapidly, which provides new ideas and tools for smart management and decision-making (Cavanillas et al., 2016). Zeyu et al. (2017) thought that the data mining is widely applied in the model study for simulation of complex systems and decision-making support. Big data recorded almost all the activities of systems which leads to a possibility of system modeling, predicting and optimizing. Thus, the Big data application or data mining methodology can help to extract the value of data and thus better decisions can be made, and the high costs of the runtime, which would make the problem intractable, can be avoided. However, the Stacey et al. (2002) point there are a number of techniques used in data mining, but not all of them can be applied to all types of data. Neural network algorithms, for example, can be used to quantify data (numerical data), but they cannot qualify data precisely (categorical data). For that the reason, one single technique cannot be used to perform a complete data mining study and each technique has its own scope of applications. For example, Neural networks can analyze imprecise, incomplete, and complex information and find important relationships or patterns from this information; by their special ability to "learn". Usually, the patterns involved in this kind of analysis are so complicated that they are not easily detected by humans or by other types of computer-based analysis. Additionally, the same is true of the data mining techniques have been applied to analyze and their corresponding causes in the efficiencies.

In addition, DEA was developed by Charnes et al. (1978) to evaluate public sector and not-for-profit organizations. It can deal with multiple inputs and outputs for measuring the performance of each DMU. Thus, Over the past few decades for the related researches, many scholars have used DEA model to analyze the operational efficiency and examine whether the widespread utilization of assessments can effectively enhance growth efficiency in order to improve operations management. Up to this point, DEA has been applied empirically to more than one thousand cases in fields as diverse as transportation, educational administration, law, forest management, medicine, banking, military maintenance, and administration. Due to an abundance of prior researches, the present study only reviewed relevant of Taiwanese literature, which revealed. We find that the most studies focused on evaluating the operational performance of universities, high schools, middle schools, vocational schools, and national elementary schools (Chen, 1998; Gu, 1999; Hwang, 
2001; Hwang, 2012; Liu, 2000; Li, 2009; Li and Kuo, 2017; Wang et al., 1991). As mentioned above, the education reforms coupled with innovative teaching which incorporates digital mobile e-learning can indeed increase students' interest in learning and their motivations and find out from the literature to use the DEA model can effectively enhance growth efficiency in order to improve operations management (Kuo et al., 2017). On the whole, not quite many researches have been relatively little progress on topics such as whether the school that introduces digital mobile e-learning can capitalize on such initiatives to enhance teaching and increase the school's competitiveness and whether there are any differences in operational efficiencies between county schools and city schools.

The use of innovative teaching techniques in the classroom has increasingly been the object of in a recent year. As mentioned above, the education reforms coupled with innovative teaching which incorporates digital mobile e-learning can indeed increase students' interest in learning and their motivations and find out from the literature to use the DEA model can effectively enhance growth efficiency in order to improve operations management.

Here, we notice that the DEA model will be some missing. Hence, many scholars believe that the application of data mining techniques to find its major and most important characteristics. For example, to use the regression analyses and dependency analysis in data describes all the important and significant dependencies among the data elements.

In other words, this study will combine with uses data mining methodology to analyze that future trends or factors affecting the relative efficiencies of schools. The main reason is about the scanty theoretical discourses on topics such as whether the school that introduces digital mobile e-learning can increase the school's competitiveness and operational efficiency. Moreover, this study will combine with uses data mining methodology to analyze that future trends or factors affecting the relative efficiencies of schools and try to solve the DEA model will be some missing. Finally, what prompted the undertaking of the current study was to better understand the actual teaching through digital mobile e-learning in the field by analyzing appropriate cases where schools embarked on self-strengthening initiatives.

\section{Methodology}

The purpose of this research is to analyze whether really improve the efficiency of school management that implemented digital mobile e-learning and teaching in an attempt to determine whether the operational efficiencies of these schools were significantly improved following digital mobile e-learning introduction. Hence, the analysis consists of a two-stage procedure. In the first part, we estimate the schools' efficiency scores through Data Envelopment Analysis, while the second study uses Big data to analyze that factors affecting the relative efficiencies of schools by utilizing related factors as explanatory variables. Finally, to used correlation is a statistical method used to assess a possible linear association between two continuous variables. In the past, no other studies have followed this approach in 
studying the efficiency of Taiwan schools. Most of the analysis that factors affecting the relative efficiencies of schools are run using the regression model.

\subsection{Study model}

\section{a. DEA}

The DEA model, proposed by Charnes, Cooper, and Rhodes (1978) and known as CCR ratio model, assumes the DMUs to be assessed operate within a technology where efficient production is characterized by constant returns to scale (CRS). As above is obtained from the following equation (1):

$$
\begin{aligned}
& \operatorname{Max} h_{k}=\frac{\sum_{r=1}^{s} u_{r} y_{r k}}{\sum_{i=1}^{m} v_{i} x_{i k}} \\
& \text { s.t } \frac{\sum_{r=1}^{s} u_{r} y_{r j}}{\sum_{i=1}^{m} v_{i} x_{i j}} \leq 1, \quad j=1, \ldots, n \\
& u_{r}, v_{i} \geq \varepsilon>0, \quad r=1, \ldots \ldots . ., s, \quad i=1, \ldots \ldots ., m
\end{aligned}
$$

Where $x_{i j}$ is the amount of the $\mathrm{i}$-th input to DMU j, $y_{r j}$ is the amount of the $\mathrm{r}$-th output to DMU $\mathrm{j} ; u_{r}, v_{i}$ are called $\mathrm{r}$ virtual multiplier output and $\mathrm{i}$ virtual input multiplier ; The value of $h_{k}$ obtained is termed the relative efficiency and is called the CCR efficiency, the $\varepsilon$ is a non-Archimedean positive element smaller any real number $\left(10^{-6}\right)$, the CCR model is called non-Archimedean small number.

Banker et al. (1984) modified this basic model to permit the assessment of the productive efficiency of DMUs where efficient production is characids by variable returns to scale (VRS). The VRS model, known as BCC, differs from the basic CCR model only in that in includes in the previous formulation the convexity constraint:

$\sum_{i=1}^{n} \lambda_{j}=1$

In summary, the following equation can be obtained for computing efficiencies:

Total $($ Technical $)$ Efficiency $(\mathrm{TE})=$ Pure Technical Efficiency $(\mathrm{PTE}) \times$ Scale Efficiency (SC)

\section{b. Pearson's product moment correlation coefficient}

In addition to this, we used correlation is a statistical method used to assess a possible linear association between two continuous variables. By the correlation 
coefficient can be explained by which represents the strength of the putative linear association between the data mining methodology and variables in question. Basic model setups can be described as follows equation (3) and in Table 1 (Mukaka, 2012):

$\mathrm{r}=\frac{\sum_{i=1}^{n}\left(x_{i}-x\right)\left(y_{i}-y\right)}{\sqrt{\left[\sum_{i=1}^{n}\left(x_{i}-\bar{x}\right)^{2}\right]\left[\left(y_{i}-\bar{y}\right)^{2}\right]}}$

Table 1: Rule of thumb for interpreting the size of a correlation coefficient

\begin{tabular}{|l|l|l|}
\hline NO & \multicolumn{1}{|c|}{ Size of correlation } & \multicolumn{1}{c|}{ Interpretation } \\
\hline $\mathbf{1}$ & .90 to $1.00(-.90$ to -1.00$)$ & Very high positive (negative) correlation \\
\hline $\mathbf{2}$ & .70 to $.90(-70$ to -.90$)$ & High positive (negative) correlation \\
\hline $\mathbf{3}$ & .50 to $.70(-.50$ to -.70$)$ & Moderate positive (negative) correlation \\
\hline $\mathbf{4}$ & .30 to $.50(-.30$ to -.50$)$ & Low positive (negative) correlation \\
\hline $\mathbf{5}$ & .00 to $.30(.00$ to -.30$)$ & Negligible correlation \\
\hline
\end{tabular}

Source: This study

\section{Empirical Results and Analysis}

The empirical analysis of this study mainly comprised two parts: firstly, this section will adopt the DEA mode to analyze the relative efficiencies of school's analysis method. Followed by the application of the DEA model and Furthermore, this study applies Data Mining Methodology to analyze the factors which include digital mobile e-learning factors that affecting the relative efficiencies of schools in various counties and cities in Taiwan.

\subsection{Results of efficiency analysis for DEA mode}

The efficiency analysis of this study mainly comprised three main sections. Section 1 describes the study objects and variable for inputs and outputs in this study. Section 2 presents data description and correlation analysis between inputs and outputs. Finally, Section 3 analyzes the efficiency analysis of DEA mode.

\subsubsection{Study objects and variable for inputs and outputs in this study}

The empirical analysis of this study mainly comprised two parts: firstly, this section will adopt the DEA model to analyze the relative efficiencies of the school's analysis method. Followed by the application of the DEA model. Furthermore, this study applies Big data to analyze the factors which include digital mobile e-learning factors that affecting the relative efficiencies of schools in various counties and cities in Taiwan.

\section{A. Study objects}

This study aimed to analyze if the introduction of digital mobile e-learning increases schools' operational efficiency and if there are any differences in students' learning 
effectiveness in school between counties and cities. The study spanned four years and included periods before and after the introduction of digital mobile e-learning as well as periods during which such introduction continued. The names, attributes, and locations (county or city) of the above schools (study objects) are outlined in Table 2:

Table 2: School names and characteristic

\begin{tabular}{|l|l|c|l|}
\hline NO & \multicolumn{1}{|c|}{ School name } & $\begin{array}{c}\text { Mobile e-learning } \\
(\mathbf{M E})\end{array}$ & City name \\
\hline $\mathbf{1}$ & Taipei First Girls High School & Yes & Taipei \\
\hline $\mathbf{2}$ & $\begin{array}{l}\text { Taipei Municipal Fuxing Senior High } \\
\text { School }\end{array}$ & Yes & Taipei \\
\hline $\mathbf{3}$ & $\begin{array}{l}\text { National Hualien Industrial } \\
\text { Vocational Senior High School }\end{array}$ & Yes & Hualien \\
\hline $\mathbf{4}$ & Chi Jen Senior High School & Yes & New Taipei \\
\hline $\mathbf{5}$ & $\begin{array}{l}\text { Taipei Municipal Lishan Senior High } \\
\text { School }\end{array}$ & Yes & Taipei \\
\hline $\mathbf{6}$ & $\begin{array}{l}\text { National Lo-Tung Senior High } \\
\text { School }\end{array}$ & Yes & I lan \\
\hline $\mathbf{7}$ & $\begin{array}{l}\text { Taipei Municipal Yang Ming Senior } \\
\text { High School }\end{array}$ & Yes & Taipei \\
\hline $\mathbf{8}$ & $\begin{array}{l}\text { Taipei Municipal Zhong-Lun Senior } \\
\text { High School }\end{array}$ & Yes & Taipei \\
\hline $\mathbf{9}$ & Juang Jing Vocational High School & Yes & New Taipei \\
\hline
\end{tabular}

Source: This study

\section{B. Variables selection for inputs and outputs in this study}

The input and output variables for the above schools that introduced digital mobile e-learning and teaching are described as follows. Input variables included four items: the number of subjects and sessions, the number of teachers, the number of parttime teachers, and the number of faculty and staff. Output variables included three items: the total population of the school, the number of graduates, and the number of graduating classes. The selection of input and output variables was also predicated on the fact that DEA is a good methodology for evaluating efficiency. The study also formulated basic hypotheses for the model. If the conditions studied failed to match the hypotheses, the utility of the model would be compromised. Hence, when applying DEA, the number of Decision-Making Units (DMUs) should be equal or greater than the multiplication of the number of inputs with the number of outputs. Otherwise, the efficiency estimated for each DMU through DEA would approximate the value of 1 and fail to discriminate among DMUs (Cooper et al., 2007). As this study adhered to this principle, operational efficiencies could be estimated and compared between schools that introduced digital mobile e-learning and those that did not.

In this paper, the input-output variables definitions of public and private vocational 
schools in the four cities, Taiwan are listed in Table 3 and Table 4. The including five input variables: academic department, number of full-time teachers, number of part-time teachers, and staff. There are three output variables: number of students, graduate's student and classes.

Table 3: Seven major indicator definition for inputs and outputs

\begin{tabular}{|l|l|c|l|}
\hline NO & \multicolumn{1}{|c|}{ Indicators } & Code & \multicolumn{1}{c|}{ Definition } \\
\hline $\mathbf{1}$ & Academic department & $x_{1}$ & $\begin{array}{l}\text { Total academic department of the } \\
\text { school. }\end{array}$ \\
\hline $\mathbf{2}$ & $\begin{array}{l}\text { Number of full-time } \\
\text { teachers }\end{array}$ & $x_{2}$ & The total number of full-time teachers. \\
\hline $\mathbf{3}$ & $\begin{array}{l}\text { Number of part-time } \\
\text { teachers }\end{array}$ & $x_{3}$ & $\begin{array}{l}\text { The total number of part-time } \\
\text { teachers. }\end{array}$ \\
\hline $\mathbf{4}$ & Staff & $x_{4}$ & The total number of staffs. \\
\hline $\mathbf{5}$ & $\begin{array}{l}\text { Number of school } \\
\text { students }\end{array}$ & $y_{1}$ & The number of school students \\
\hline $\mathbf{6}$ & Graduate student & $y_{2}$ & The number of graduate students. \\
\hline $\mathbf{7}$ & Classes & $y_{3}$ & The number of school classes. \\
\hline
\end{tabular}

Source: This study

Table 4: DEA model Input and output indicators definitions

\begin{tabular}{|l|l|c|c|}
\hline NO & \multicolumn{1}{|c|}{ Indicators } & Code & Definition \\
\hline $\mathbf{1}$ & Academic department & $x_{1}$ & Input Indicator \\
\hline $\mathbf{2}$ & $\begin{array}{l}\text { Number of full-time } \\
\text { teachers }\end{array}$ & $x_{2}$ & Input Indicator \\
\hline $\mathbf{3}$ & $\begin{array}{l}\text { Number of part-time } \\
\text { teachers }\end{array}$ & $x_{3}$ & Input Indicator \\
\hline $\mathbf{4}$ & Staff & $x_{4}$ & Input Indicator \\
\hline $\mathbf{5}$ & $\begin{array}{l}\text { Number of school } \\
\text { students }\end{array}$ & $y_{1}$ & Output Indicator \\
\hline $\mathbf{6}$ & Graduate student & $y_{2}$ & Output Indicator \\
\hline $\mathbf{7}$ & Classes & $y_{3}$ & Output Indicator \\
\hline
\end{tabular}

Source: This study

\subsubsection{Data descriptions and correlation analysis between inputs and outputs}

The section is divided into two main sections. Section 1 describes data descriptions. Section 2 presents the correlation analysis between inputs and outputs in this study.

\section{A. Data descriptions}

Descriptive statistics were calculated. Ultimately, data was collected on several variables of interest for 27 out of the 9 schools for three years. The list of variables and their summary statistics are presented listed in Table 5. 
Table 5: Descriptive statistics

\begin{tabular}{|l|c|c|c|c|c|}
\hline & Minimum & Maximum & Mean & SD & Variance \\
\hline Academic department & 1.00 & 3.00 & 1.78 & 0.93 & 0.87 \\
\hline $\begin{array}{l}\text { Number of full-time } \\
\text { teachers }\end{array}$ & 70.00 & 195.00 & 143.11 & 38.97 & 1518.64 \\
\hline $\begin{array}{l}\text { Number of part-time } \\
\text { teachers }\end{array}$ & 1.00 & 73.00 & 17.70 & 19.62 & 385.06 \\
\hline Staff & 17.00 & 80.00 & 30.59 & 16.87 & 284.64 \\
\hline $\begin{array}{l}\text { Number of school } \\
\text { students }\end{array}$ & 723.00 & 4729.00 & 1962.33 & 1115.21 & 1243700.77 \\
\hline Graduate student & 294.00 & 1146.00 & 598.96 & 274.68 & 75447.96 \\
\hline Classes & 18.00 & 109.00 & 53.19 & 25.77 & 664.00 \\
\hline
\end{tabular}

Source: This study

\section{B. Correlation analysis between inputs and outputs}

This study employed Pearson correlation analysis to first analyze the degree of correlation between input and output variables and removed variables with negative correlations. Another correlation analysis was then conducted to ensure positive correlations between the variables selected and adherence to the estimation principle of DEA.

Finally, the input variables chosen were the number of teachers, the number of parttime teachers, and the number of faculty and staff, while the output variables chosen were the total population of the school, the number of graduates, and the number of graduating classes. The results of final correlation analysis are displayed in Table 6 .

Table 6: Correlation test and analysis

\begin{tabular}{|c|c|c|c|c|c|c|}
\hline & $\boldsymbol{x}_{\mathbf{2}}$ & $\boldsymbol{x}_{\mathbf{3}}$ & $\boldsymbol{x}_{\mathbf{4}}$ & $\boldsymbol{y}_{\mathbf{1}}$ & $\boldsymbol{y}_{\mathbf{2}}$ & $\boldsymbol{y}_{\mathbf{3}}$ \\
\hline $\boldsymbol{x}_{\mathbf{2}}$ & 1 & .421 & .528 & .819 & .825 & .815 \\
\hline $\boldsymbol{x}_{\mathbf{3}}$ & & 1 & .855 & .775 & .583 & .773 \\
\hline $\boldsymbol{x}_{\mathbf{4}}$ & & & 1 & .792 & .567 & .761 \\
\hline $\boldsymbol{y}_{\mathbf{1}}$ & & & & 1 & .905 & .978 \\
\hline $\boldsymbol{y}_{\mathbf{2}}$ & & & & & 1 & .867 \\
\hline $\boldsymbol{y}_{\mathbf{3}}$ & & & & & & 1 \\
\hline
\end{tabular}

Source: This study

\subsubsection{Efficiency analysis}

Regarding efficiency analysis, Section 1 analyzes total technical efficiency (TE), Section 2 indicates pure technical efficiency (PTE) and Section 3 describes scale efficiency (SE). 


\section{A. Total technical efficiency (TE)}

As shown in Table 7 below after imported digital mobile e-learning. Since the introduction of digital mobile e-learning in 2012, only four out of the nine schools in four counties and cities reached an overall total technical efficiency rate of "1" for three years in a row, including the Taipei First Girls' High School, Taipei Municipal Fuxing Senior High School, Taipei Municipal Lishan Senior High School, and Juang Jing Vocational High School. On the other hand, the remaining five schools failed to reach the efficiency rate of "1", including the National Hualien Industrial Vocational High School, Chi Jen High School, National Lo-Tong Senior High School, National Yang Ming Senor High School, and Taipei Municipal Zhong-Lun High School. This result demonstrates that the introduction of digital mobile e-learning does not necessarily affect a school's operational efficiency in spite of the school's more robust connection to the network. For example, the operational efficiency of the Taipei Municipal Zhong-Lun High School is actually lower than that of other schools, despite the introduction of digital learning during 2013 and 2014.

Table 7: Total technical efficiency analysis of high schools in this study

\begin{tabular}{|c|c|c|c|c|c|}
\hline DMU & $\mathbf{2 0 1 3}$ & $\mathbf{2 0 1 4}$ & $\mathbf{2 0 1 5}$ & Average & Ranking \\
\hline $\mathbf{1}$ & 1 & 1 & 1 & 1 & 1 \\
\hline $\mathbf{2}$ & 1 & 1 & 1 & 1 & 1 \\
\hline $\mathbf{3}$ & 0.838 & 0.848 & 0.796 & 0.827 & 8 \\
\hline $\mathbf{4}$ & 1 & 1 & 0.955 & 0.985 & 5 \\
\hline $\mathbf{5}$ & 1 & 1 & 1 & 1 & 1 \\
\hline $\mathbf{6}$ & 1 & 0.784 & 0.758 & 0.847 & 7 \\
\hline $\mathbf{7}$ & 1 & 1 & 0.797 & 0.932 & 6 \\
\hline $\mathbf{8}$ & 0.578 & 0.637 & 0.985 & 0.733 & 9 \\
\hline $\mathbf{9}$ & 1 & 1 & 1 & 1 & 1 \\
\hline
\end{tabular}

Source: This study

\section{B. Pure technical efficiency (PTE)}

As shown by the data in Table 8 on pure technical efficiency, the efficiency rates of five out of the nine schools in four counties and cities that introduced digital learning for three years in a row reached "1", including the Taipei First Girls' High School, Taipei Municipal Fuxing Senior High School, Chi Jen High School, Taipei Municipal Lishan Senior High School, and Juang Jing Vocational High School. All these schools are located in Taipei City or New Taipei City. This result shows that these schools utilized their resources effectively and did not need to make any further adjustment or improvement, when external factors were excluded. On the other hand, the efficiency rates of the remaining four schools were below "1", including the National Hualien Industrial Vocational High School, National LoTong Senior High School, National Yang Ming Senor High School, and Taipei Municipal Zhong-Lun High School. These schools all needed to make further 
improvement or adjustment, when external factors were excluded. This result shows that differentials in resources do exist across counties and cities, which could impact the pure technical efficiency of schools. This explains why the efficiency rates of some schools are lower than " 1, " that is, because of the county or city where they are located.

\section{Scale efficiency (SE)}

As shown by the results in Table 9 on scale efficiency, the efficiency rates of four out of the nine schools in four counties and cities that introduced digital learning for three years in a row reached "1", including the Taipei First Girls' High School, Taipei Municipal Fuxing Senior High School, Taipei Municipal Lishan Senior High School, and Juang Jing Vocational High School. All these schools are located in Taipei City or New Taipei City. On the other hand, the five remaining schools failed to reach the efficiency rate of " 1 ", including the National Hualien Industrial Vocational High School, Chi Jen High School, National Lo-Tong Senior High School, National Yang Ming Senor High School, and Taipei Municipal Zhong-Lun High School. The Taipei Municipal Zhong-Lun High School was the only school with declining returns to scale. Hence, in order to optimize its scale of operation, the school needs to reduce its scale. Too many resources may have rendered the school's operation inefficient. With increasing returns to scale, the other schools need to expand their scales of operation in order to reach the optimal scale efficiency. They have not received sufficient resources, which also renders schools' operations inefficient.

Table 8: Pure technical efficiency analysis high schools in this study

\begin{tabular}{|c|c|c|c|c|c|}
\hline DMU & $\mathbf{2 0 1 3}$ & $\mathbf{2 0 1 4}$ & $\mathbf{2 0 1 5}$ & Average & Ranking \\
\hline $\mathbf{1}$ & 1 & 1 & 1 & 1 & 1 \\
\hline $\mathbf{2}$ & 1 & 1 & 1 & 1 & 1 \\
\hline $\mathbf{3}$ & 0.850 & 0.856 & 0.826 & 0.845 & 9 \\
\hline $\mathbf{4}$ & 1 & 1 & 1 & 1 & 1 \\
\hline $\mathbf{5}$ & 1 & 1 & 1 & 1 & 1 \\
\hline $\mathbf{6}$ & 1 & 0.917 & 0.869 & 0.929 & 7 \\
\hline $\mathbf{7}$ & 1 & 1 & 0.956 & 0.985 & 6 \\
\hline $\mathbf{8}$ & 0.761 & 0.774 & 1 & 0.845 & 8 \\
\hline $\mathbf{9}$ & 1 & 1 & 1 & 1 & 1 \\
\hline
\end{tabular}

Source: This study 
Table 9: Scale efficiency analysis of high schools

\begin{tabular}{|c|c|c|c|c|c|c|}
\hline DMU & $\mathbf{2 0 1 3}$ & $\mathbf{2 0 1 4}$ & $\mathbf{2 0 1 5}$ & Average & $\begin{array}{c}\text { Returns to scale } \\
\text { (RTS) }\end{array}$ & Ranking \\
\hline $\mathbf{1}$ & 1 & 1 & 1 & 1 & Constant & 1 \\
\hline $\mathbf{2}$ & 1 & 1 & 1 & 1 & Constant & 1 \\
\hline $\mathbf{3}$ & 0.987 & 0.991 & 0.963 & 0.980 & Increasing & 9 \\
\hline $\mathbf{4}$ & 1 & 1 & 0.954 & 0.985 & Increasing & 1 \\
\hline $\mathbf{5}$ & 1 & 1 & 1 & 1 & Constant & 1 \\
\hline $\mathbf{6}$ & 1 & 0.855 & 0.871 & 0.909 & Increasing & 7 \\
\hline $\mathbf{7}$ & 1 & 1 & 0.833 & 0.944 & Increasing & 6 \\
\hline $\mathbf{8}$ & 0.760 & 0.823 & 0.985 & 0.856 & Decreasing & 8 \\
\hline $\mathbf{9}$ & 1 & 1 & 1 & 1 & Constant & 1 \\
\hline
\end{tabular}

Source: This study

\subsubsection{Data mining methodology}

We in order to solve its black boxes problem of the DEA model. Therefore, to perform data mining methodology and attempt to find determinants affecting school efficiency. Section 1 describes the data mining methodology step. Section 2 parameter setting for data mining methodology. Lastly, discusses the empirical results of data mining methodology and attempt to find determinants affecting school efficiency.

\subsubsection{Model step}

First of all, this section describes data mining methodology steps of in school efficiency.

Step 1: To perform the estimating school efficiency of used DEA model.

Step 2: To list of we focus the major variables that relate to the determinants of mobile digital e-learning.

Step 3: To select school efficiency and major variables of mobile digital elearning.

Step 4: To perform data mining methodology and to find determinants affecting school efficiency.

\subsubsection{Major variables in school efficiency}

The analysis was conducted using the data mining methodology and we used a different focus on the major variables depending. However, these variables have according to the related theories and literature provided useful information in this study, it is indicated that the variables usually be used related researches, and we focus the major variables that relate to the determinants of mobile digital e-learning. Basic model setups can be described as follows (Kuo et al., 2017):

Basic model setups can be described as following equation (4): 
$T E_{i t}=f\left(\boldsymbol{Z}_{\mathbf{1}_{i t}}, \boldsymbol{Z}_{\mathbf{2}_{i t}}, \boldsymbol{Z}_{\mathbf{3}_{i t}}, \boldsymbol{Z}_{\mathbf{4}_{i t}}, \boldsymbol{Z}_{\mathbf{5}_{i t}}, \boldsymbol{Z}_{\mathbf{6}_{i t}}, \boldsymbol{Z}_{\mathbf{7}_{i t}}\right)$

The theoretically expected signs of the coefficients are:

$\beta_{1}>0, \beta_{2}>0, \beta_{3}>0, \beta_{4}>0, \beta_{5}>0, \beta_{6}>0, \beta_{7}>0$

Where

$\boldsymbol{T} \boldsymbol{E}_{i t}$ : Technical efficiency for management of School i during the period 2013 to 2015

$\boldsymbol{Z}_{\mathbf{1}_{i t}}$ : School size (total numbers of school students) of School i

$\boldsymbol{Z}_{\mathbf{2}_{\text {it }}}$ : Teacher-student ratio (average number of students per teacher members) of School i

$\boldsymbol{Z}_{\mathbf{3}_{\text {it }}}$ : The total number of tablet PC of School i

$\boldsymbol{Z}_{\mathbf{4}_{i t}}$ : Technical teacher ratio (measured by the ratio for the numbers of technicians as consultants for teaching tablet PC knowledge to total number of teachers in school) of School i

$\boldsymbol{Z}_{\mathbf{5}_{i t}}$ : Total equipment expenses associated with tablet PC of School i

$\boldsymbol{Z}_{\mathbf{6}_{i t}}$ : School location dummy: in the northern area: 1 , other areas: 0

$\boldsymbol{Z}_{\mathbf{7}_{i t}}$ : School attribute dummy: public high schools: 1 , private high schools: 0

As mentioned above, we describe data mining methodology sources and model settings of Big data application in school efficiency through innovative teaching via digital mobile e-learning and shown in Figure 1. 


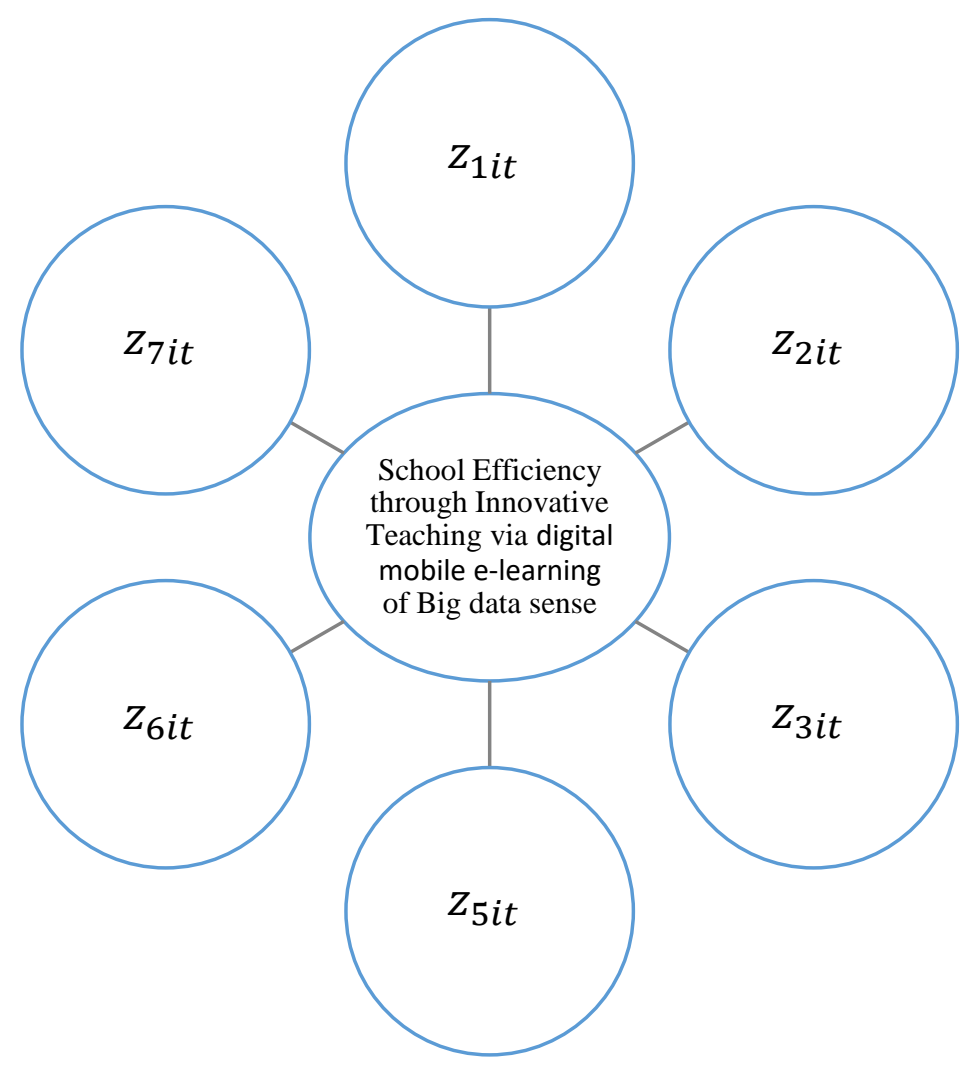

Figure 1: Model settings

\subsubsection{Results of data mining methodology explaining to determinants affecting school efficiency}

According to the result of the experimental and shown as follow:

Table 10: Results of data mining methodology

\begin{tabular}{|c|c|l|}
\hline Variable & Size of correlation & \multicolumn{1}{|c|}{ Interpretation } \\
\hline $\boldsymbol{Z}_{\mathbf{1}}$ & 0.005 & Negligible correlation \\
\hline $\boldsymbol{Z}_{\mathbf{2}}$ & -0.641 & Moderate negative correlation \\
\hline $\boldsymbol{Z}_{\mathbf{3}}$ & -0.565 & Moderate negative correlation \\
\hline $\boldsymbol{Z}_{\mathbf{4}}$ & 0.785 & High positive correlation \\
\hline $\boldsymbol{Z}_{\mathbf{5}}$ & -0.752 & High negative correlation \\
\hline $\boldsymbol{Z}_{\mathbf{6}}$ & 0.687 & Moderate positive correlation \\
\hline $\boldsymbol{Z}_{\mathbf{7}}$ & -0.597 & Moderate negative correlation \\
\hline
\end{tabular}

Source: This study 


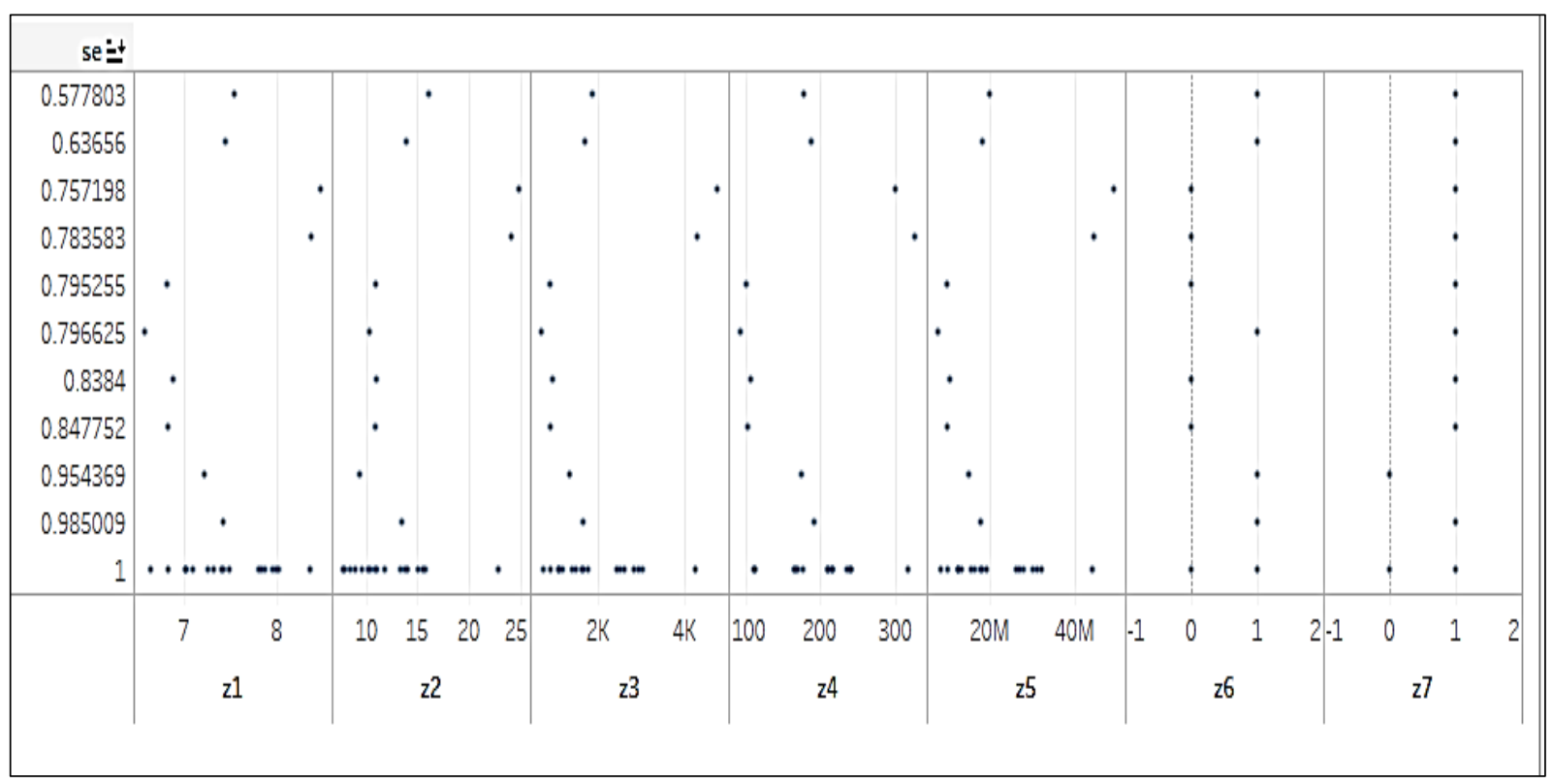

Figure 2: Results of data mining methodology

1) School size: $\left(\boldsymbol{Z}_{\mathbf{1}}\right)$

According to the empirical results shown in Table 10 and Figure 2, the effect of school size of the Pearson's correlation coefficient for these variables is 0.005 . The result of the experiment that a correlation coefficient of 0.005 is considered to be negligible correlation. Owing to Taiwan is facing the challenge of a low birth rate which also significantly impacts educational institutes, particularly in terms of how well school size. Due to, the number of students has decreased, and the size of the school will also shrink. The number of students participating in digital learning will naturally decline. Hence, the effect of school size on school's operational efficiency may not significant. The study of Ozdamli and Cavus (2011) also not the same our analysis.

2) Teacher-student ratio $\left(\boldsymbol{Z}_{\mathbf{2}}\right)$

Based on empirical results shown in Table 10 and Figure 2. The effect of the teacher-student ratio of the Pearson's correlation coefficient for these variables is 0.641 . The result of the experiment that a correlation coefficient of -0.641 is a moderate negative correlation. One of the main reasons that the low fertility problem in Taiwan, the number of students will be decreased and overestimate the teacher-student ratio. i e., class size decreases and leads to too many teachers as input in each class. Therefore, resource misallocation in teachers and students and the cost per teacher over counts and hence reduce the school's operational efficiency. Previous research of Badri and El (2012) supports our findings. 
3) Tablet PC numbers: $\left(\boldsymbol{Z}_{\mathbf{3}}\right)$

As can be seen that the results shown in Table 10 and Figure 2. The effect of tablet PC numbers of the Pearson's correlation coefficient for these variables is -0.565 . The result of the experiment that a correlation coefficient of -0.565 is is a moderate negative correlation. The innovative teaching to affect school efficiency through using digital mobile e-learning by Tablet PC enable learners to be in the right place at the right time, that is, to be where they are able to experience the authentic joy of learning and attract students join. As results, the more Tablet PC numbers to be applied in high school will cause the school's operational efficiency. Our result is consistent with Ozdamli and Cavus (2011) justified that a successfully attract students to join digital mobile e-learning and then cause school's operational efficiency.

\section{4) Technical teacher ratio: $\left(\boldsymbol{Z}_{\mathbf{4}}\right)$}

According to the estimated results shown in Table 10 and Figure 2. The effect of technical teacher ratio (measured by the ratio for the numbers of technicians as consultants for teaching tablet PC knowledge total number of teachers in school) of the Pearson's correlation coefficient for these variables is 0.785 . The result of the experiment that a correlation coefficient of 0.785 is a high positive correlation. When participating in digital mobile e-learning in more schools, students will be attracted to study. More technical teacher guidance is needed at this time. Thus, when students increase and they must an increase in the technical teacher ratio may also add to them, even more, school students to apply this digital mobile e-learning program, when ratio for the numbers of technicians as consultants for teaching tablet PC knowledge total number of teachers in school expand, they are able to cause school's operational efficiency. The study of Ozdamli and Cavus (2011) also supports our analysis that a successful digital mobile e-learning integration, to induce increasing more persons learn such as school students to apply this digital mobile e-learning.

\section{5) Total equipment expenses associated with tablet PC: $\left(\boldsymbol{Z}_{\mathbf{5}}\right)$}

Based on the estimated results shown in Table 10 and Figure 2. The effect of total equipment expenses associated with tablet PC on school's operational efficiency of the Pearson's correlation coefficient for these variables is -0.752 . The result of the experiment that a correlation coefficient of -0.752 is a High negative correlation. In general, mobile e-learning (mobile-e-learning) as a kind of learning model allowing learners to obtain learning materials anywhere and anytime. At this point, more communication equipment needs to be built. Therefore, the learning effect can be improved of students. However, when the number of students is reduced, the equipment maintenance costs will be a serious expense. In addition, as indicated by the studies of Ozdamli and Cavus (2011) and the communication equipment need to be constructed well and completely. Our empirical results indicate that the total equipment expenses associated with tablet $\mathrm{PC}$ have a negative influence on school management efficiency due to the increasing costs for furnishing the related internet 
and network equipment or device to facilitate for teaching and learning among teachers and students by digital mobile e-learning.

6) School location: $\left(\boldsymbol{Z}_{\mathbf{6}}\right)$

The effect of school location on school's operational efficiency of the Pearson's correlation coefficient for these variables is 0.687 shown in Table 10 and Figure 2. The result of the experiment that a correlation coefficient of 0.687 is a moderate positive correlation. When the school promotes mobile digital e-learning, the school needs to build more communication equipment. In order to improve the learning effect of students. However, school units need to invest a lot of money to build equipment. Therefore, when the school is located in a big city (such as Taipei City), there are more resources to build communication equipment. In addition, as indicated by the studies of (Liu et al., 2016).

7) School attribute $\left(\boldsymbol{Z}_{\mathbf{7}}\right)$

The effect of school attribute on school's operational efficiency of the Pearson's correlation coefficient for these variables is -0.597 shown in Table 9 and Figure 2. The result of the experiment that a correlation coefficient of -0.597 is a moderate negative correlation. In this study, we consider whether the public or private school has different operational efficiency. Our empirical results depict that operational efficiency of public school is better than that of private school. The public-school accessory equipment comes from the budget of the central government, but the private school accessory equipment of budget comes from oneself school. When the school promotes mobile digital e-learning, the school needs to build more communication equipment. Therefore, when the economy is not good and the government does not have a budget, the equipment installed by the school unit will become a fixed expenditure for the public school. Therefore, the degree of school's operational efficiency also needs to be considered their school attributes such as equipment, teaching quality, management decisions and etc. (Liu et al., 2016).

\section{Concluding remarks}

In this study, we firstly it investigates apply DEA model to analyze the operational efficiency of high school in Taiwan sector by estimating three efficiency estimators, namely Technical Efficiency (TE), Pure Technical Efficiency (PTE) and Scale Efficiency (SE) and to results of data mining methodology explaining to determinants affecting school efficiency.

Based on our empirical results from DEA method, only four out of the nine schools in four counties and cities reached an overall technical efficiency (TE) rate of " 1 " for three years in a row, including the Taipei First Girls' High School, Taipei Municipal Fuxing Senior High School, Taipei Municipal Lishan Senior High School, and Juang Jing Vocational High School. All these schools are located in Taipei City or New Taipei City.

The research shows and these four of the efficiency schools. Among them, three are 
public schools and are located in Taipei city. The results show that Public schools are better than private schools. on the other hand, when the school is located in big cities (such as Taipei city) do have more resources to promote mobile digital elearning.

Lastly, we also apply the data mining methodology to find that the teacher-student ratio, tablet $\mathrm{PC}$ numbers, technical teacher ratio, the total equipment expenses associated with tablet PC, School location and School attribute are important determinants for affecting the efficiency of school management. Our empirical results and when the school promote mobile digital e-learning, the school needs to build more communication equipment. Therefore, school units need more teachers or technical teachers, but when students are reduced, this communication equipment will become fixed costs for the school. Studies have shown that the location of the school will help with the maintenance of the school's facilities. Therefore, when the economy is not good and the government does not have a budget, the equipment built by public school units will become a fixed expenditure for the school. Instead, it reduces the efficiency of school operations.

Lastly, the conclusions and recommendations presented here are based on the models constructed, sample data collected, and research methodologies employed for this study. Hence, it is necessary to take into consideration the current situation and changes in the environment that are impacting the different schools in the Taiwan District, so any application of our findings can be further tailored to yield more accurate conclusions. 


\section{References}

[1] Agrawal, R., Imieliński, T., and Swami, A. (1993). Mining Association Rules between Sets of Items in Large Databases. In Acm sigmod record, 22(2), pp. 207-216). ACM.

[2] Al-Emran, M., Elsherif, H. M., and Shaalan, K. (2016). Investigating Attitudes Towards the Use of Mobile Learning in Higher Education. Computers in Human Behavior, 56, pp. 93-102.

[3] Banker, R. D., Charnes, A., and Cooper, W. W. (1984). Some Models for the Estimation of Technical and Scale Inefficiencies in Data Envelopment Analysis. Management Science, 30(9), pp. 1078-1092.

[4] Banister, S. (2010). Integrating the iPod Touch in K-12 Education: Visions and vices. Computers in the Schools, 27(2), pp. 121-131. doi:10.1080/07380561003801590.

[5] Berry, M. J., and Linoff, G. (1997). Data Mining Techniques: for Marketing, Sales, and Customer Support. John Wiley \& Sons, Inc.

[6] Cavanillas, J. M., Curry, E., and Wahlster, W. (2016). New Horizons for a Data-Driven Economy: A Roadmap for Usage and Exploitation of Big Data in Europe. Springer.

[7] Charnes, A., Cooper, W. W., and Rhodes, E. (1978). Measuring the Efficiency of Decision-Making Units. European Journal of Operational Research, 2(6), pp. 429-444.

[8] Chen, R. F. (1998). Evaluation of Educational Quality in Universities and Colleges in Taiwan Using Data Envelopment Analysis. Academic Journal of Kaohsiung Institute of Science and Technology, 28, pp. 227-238.

[9] Chiang, W. M. (2009). Impact of Low Birth Rate on High School Education and Recommendations. Secondary Education Monthly, 60(1), pp. 26-34.

[10] Cook, W. D., Tone, K., and Zhu, J. (2014). Data Envelopment Analysis: Prior to Choosing a Model. OMEGA, 44, pp. 1-4.

[11] Chen, L., and Jia, G. (2017). Environmental Efficiency Analysis of China's Regional Industry: A Data Envelopment Analysis (DEA) Based Approach. Journal of Cleaner Production, 142 (2), pp. 846-853.

[12] El-Gayar, O. F., Moran, M., and Hawkes, M. (2011). Students' Acceptance of tablet PCs and Implications for Educational Institutions. Educational Technology \& Society, 14(2), pp. 58-70.

[13] Eristi, S. D., Haseski, H. I., Uluuysal, B., and Karakoyun, F. (2011). The Use of Mobile Technologies in Multimedia-Supported Learning Environments. The Turkish Online Journal of Distance Education, 12(3), 130-141.

[14] Färe, R., and Grosskopf, S. (2000). Network DEA. Socio-Economic Planning Sciences, 34 (1), pp. 35-49.

[15] Farzipoor Saen, R. (2010). Developing a New Data Envelopment Analysis Methodology for Supplier Selection in the Presence of Both Undesirable Outputs and Imprecise Data. Int. J. Adv. Manuf. Technol, 51 (9), pp. 12431250. 
[16] Garrett, R. M. (2010), Education and Development, Routledge, London.

[17] Gu, Z. Y., (1999). A study on the Productivity Assessment and Integration Model of Resource Allocation in Higher Education Units. Journal of Management and Systems, 6(3), pp. 347-364.

[18] Gursul, F., and Tozmaz, G. B. (2010). Which one is Smarter? Teacher or Board. Procedia-Social and Behavioral Sciences, 2(2), pp.5731-5737.

[19] Gikas, J., and Grant, M. M. (2013). Mobile Computing Devices in Higher Education: Student Perspectives on Learning with Cellphones, Smartphones \& Social Media. The Internet and Higher Education, 19, 18-26.

[20] Han, J., Kamber, M., and Pei, J. (2006). Data Mining: Concepts and Techniques, (the Morgan Kaufmann Series in Data Management Systems). 230-240.

[21] Hwang, G. J., Tsai, C. C., and Yang, S. J. H. (2008). Criteria, Strategies and Research issues of Context-Aware Ubiquitous learning. Educational Technology and Society, 11(2), pp. 81-91.

[22] Hwang, J. X. (2001). Evaluating the Efficiencies of National High Schools in Taiwan: Application of Data Envelopment Analysis (MA Thesis unpublished), Chiayi City: National Chung Cheng University.

[23] Hwang, Y. X. (2012). Comparative Analysis of the Operational Performance of Public and Private High Schools, Middle Schools, and Vocational Schools with Schools in the Sindian District of New Taipei City as Examples (MA Thesis - unpublished), Taichung: Asia University.

[24] Ifenthaler, D., and Schweinbenz, V. (2013a). The Acceptance of Tablet-PCs in Classroom Instruction: The Teachers' perspective. Computers in Human Behavior, 29(3), pp. 525-534. doi: 10.1016/j.chb.2012.11.004.

[25] Ifenthaler, D., and Schweinbenz, V. (2013b). Students' Acceptance of TabletPCs in the Classroom. In AERA 2013: Education and Poverty: Theory, Research, Policy, and Praxis: Proceedings of the American Education Research Association 2013 Annual Meeting (pp. 1-1). American Education Research Association.

[26] Kuo, F. H. and Liu, H. H. (2017). Upgrading School Efficiencies and Learning Interests through Innovative Teaching of Digital Mobile E-Learning. Journal of Social and Administrative Sciences, 4(4), pp. 382-397.

[27] Lawrence, S. D. (2012). iPad Use in Schools on the Rise. Education News. Retrieved from http://www.educationnews.org/technology/ipad-use-inschools-on-the-rise/

[28] Liu, C. H., and Ch'en, W. Y. (2009). Research on Mobile Learning Experimental Systems. Paper Presented at the Conference of Digital Technology and Innovation Management, Taipei, Huafan University.

[29] Liu, M. C. (2000). A Study on the Assessment of the Management Efficiencies of Education at Vocational High Schools in Taiwan: Applied Analysis of the DEA Model (MA Thesis - unpublished), Nantou County: National Chi Nan University. 
[30] Liu, H. H., and Kuo, F. H. (2017). Operating Efficiency and its Effect from Innovative Teaching through Digital Mobile E-Learning for Public and Private High Schools. Research in Applied Economics, 9(3), pp. 70-90.

[31] Martin, S., Diaz, G., Sancristobal, E., Gil, R., Castro, M., and Peire, J. (2011). New technology trends in education: Seven Years of Forecasts and Convergence. Computers \& Education, 57(3), pp. 1893-1906.

[32] McAfee, A., and Brynjolfsson, E. (2012). Big Data: The Management Revolution. Harvard Business Review. Rev. 90 (10), 60-69.

[33] Mukaka, M. (2012). A guide to appropriate use of Correlation coefficient in medical research. Malawi Medical Journal: The Journal of Medical Association of Malawi, 24(3), pp. 69-71.

[34] Norman, M., and Stoker, B. (1991). Data Envelopment Analysis: The Assessment of Performance. John Wiley \& Sons, Chichester, NY.

[35] Ohlhorst, F. J. (2012). Big Data Analytics: Turning Big Data into Big Money. New York: Wiley.

[36] Priyadharsini, C., and Thanamani, A. S. (2014). An Overview of Knowledge Discovery Database and Data mining Techniques. International Journal of Innovative Research in Computer and Communication Engineering, 2(1). 1571- pp. 1578

[37] Price, S., Jewitt, C., and Crescenzi, L. (2015). The Role of iPads in Pre-School Children's Mark Making Development. Journal Computers \& Education, 87, pp. 131-141.

[38] Rohanizadeh, S. S., and Bameni, M. M. (2009). A Proposed Data Mining Methodology and its Application to Industrial Procedures. Journal of Industrial Engineering, 4, pp. 37-50.

[39] Simsek, A., I'skenderog lu, T., and I’skenderog `lu, M. (2010). Investigating Pre-service Computer Teachers' Attitudes Towards Distance Education. Procedia-Social and Behavioral Sciences, 9, pp. 324-328. doi:10. 1016/j.sbspro.2010.12.158.

[40] Suki, N. M., and Suki, N. M. (2011). Users' Behavior Towards Ubiquitous MLearning. The Turkish Online Journal of Distance Education, 12(3), pp. 118129.

[41] Stacey, B., Michelle D., Cooch, J., and Paul, R. (2002). Data Mining. University of Iowa, pp. 26-43.

[42] Tate, C. (2012). Schools Across the Country Bring iPads to the Classroom. Retrieved from: http://www.mcclatchydc.com/2012/03/27/143268/schoolsacross-the-country-bring.html

[43] Vallurupalli, S., Paydak, H., Agarwal, S. K., Agrawal, M., and Assad-Kottner, C. (2013). Wearable Technology to Improve Education and Patient Outcomes in a Cardiology Fellowship Program-a Feasibility Study. Health and Technology, 3(4), pp. 267-270.

[44] Wang, G. M. and Gu, Z. Y. (1991). A Study on the Application of DEA in Educational Assessment. Modern Education, 6(1), pp. 118-127. 
[45] Williams, A. J., and Pence, H. E. (2011). Smart Phones, a Powerful Tool in the Chemistry Classroom. Journal of Chemical Education, 88(6), pp. 683-686.

[46] Zeyu, J., Shuiping, Y., Mingduan, Z., Yongqiang, C., and Yi, L. (2017). Model Study for Intelligent Transportation System with Big Data. Procedia Computer Science, 107, pp. 418-426. 